Research Paper

\title{
Efficacy of Single-Dose Dexmedetomidine Combined with Low-Dose Remifentanil Infusion for Cough Suppression Compared to High-Dose Remifentanil Infusion: A Randomized, Controlled, Non-Inferiority
} Trial

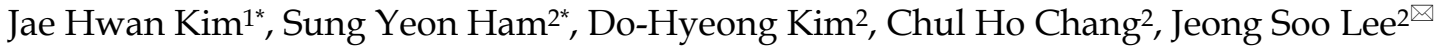 \\ 1. Department of Anesthesiology and Pain Medicine, Korea University, Ansan Hospital, Kyung-gi-do, Korea \\ 2. Department of Anesthesiology and Pain Medicine, Anesthesia and Pain Research Institute, Yonsei University College of Medicine, Seoul, Republic of Korea \\ *These authors contributed equally to this work \\ $\square$ Corresponding author: E-mail: ration99@yuhs.ac
}

(c) Ivyspring International Publisher. This is an open access article distributed under the terms of the Creative Commons Attribution (CC BY-NC) license (https://creativecommons.org/licenses/by-nc/4.0/). See http://ivyspring.com/terms for full terms and conditions.

Received: 2018.09.26; Accepted: 2018.12.17; Published: 2019.01.24

\begin{abstract}
Background: Combination of dexmedetomidine and opioid may be an alternative to high-dose opioid in attenuating cough during emergence from anesthesia, while also reducing the adverse effects of high-dose opioid. We tested the hypothesis that a single-dose of dexmedetomidine combined with low-dose remifentanil infusion during emergence would not be inferior to high-dose remifentanil infusion alone in attenuating cough after thyroidectomy.

Methods: One hundred sixty-nine patients undergoing thyroidectomy were enrolled and randomized in a 1:1 ratio into group DR or group $R$. Each patient received an infusion of dexmedetomidine $(0.5 \mu \mathrm{gg} / \mathrm{kg})$ and low-dose remifentanil infusion of effect-site concentration $(\mathrm{Ce})$ at $1 \mathrm{ng} / \mathrm{mL}$ or normal saline and high-dose remifentanil infusion of $\mathrm{Ce}$ at $2 \mathrm{ng} / \mathrm{mL}$ for $10 \mathrm{~min}$ at the end of surgery. Remifentanil was maintained until tracheal extubation. Primary endpoint was the severity of coughing, which was assessed for non-inferiority using a four-point scale at the time of extubation. For comparison of coughing incidence during emergence, coughing grade was also measured at three times: before extubation, at extubation, and after extubation. Time to awakening, hemodynamic and respiratory profile, pain, and postoperative nausea and vomiting were also evaluated for superiority.

Results: The $95 \%$ confidence intervals for differences in cough grade during tracheal extubation were $<0.9$, indicating non-inferiority of the single dose of dexmedetomidine combined with low-dose remifentanil infusion. The incidence of coughing was similar in the two groups. Hemodynamic changes during tracheal extubation were attenuated, but emergence from anesthesia was delayed, in group DR. Use of rescue antiemetic was similar in both groups, but the incidence of vomiting was less in group DR.

Conclusion: A single-dose of dexmedetomidine $(0.5 \mu \mathrm{g} / \mathrm{kg})$ combined with low-dose remifentanil infusion at $1 \mathrm{ng} / \mathrm{mL}$ of Ce during emergence from sevoflurane-remifentanil anesthesia was not inferior to high-dose remifentanil infusion alone at $2 \mathrm{ng} / \mathrm{mL}$ of Ce with regard to suppressing cough.
\end{abstract}

\section{Introduction}

Coughing during emergence from general anesthesia is a critical issue in patient care in the perioperative period [1] as it may lead to surgical

bleeding, laryngospasm, and cardiovascular instability. Maintenance of remifentanil infusion, which is conventionally used as an adjuvant in 
general anesthesia, attenuates coughing during emergence in dose-related manner [2]. However, further increasing the dose of remifentanil may cause respiratory depression, delayed emergence, and aggravate postoperative nausea and vomiting.

Dexmedetomidine is a highly selective $\mathrm{a}_{2}$-adrenoreceptor agonist that has sedative, analgesic, and sympatholytic properties, without respiratory depression [3, 4]. A previous study showed that addition of a single dose of dexmedetomidine (0.5 $\mu \mathrm{g} / \mathrm{kg}$ ) during emergence was more effective in preventing cough than remifentanil infusion alone [5]. However, the remifentanil dose in this study was an insufficient amount to suppress coughing during emergence, compared to previous studies. Therefore, it remains unknown whether the addition of singledose dexmedetomidine to low-dose remifentanil infusion is as effective as high-dose remifentanil infusion alone for suppressing emergence cough and whether it may also reduce the adverse events related to high-dose opioids.

Therefore, we hypothesized that a single dose of dexmedetomidine $(0.5 \mu \mathrm{g} / \mathrm{kg})$ combined with low-dose remifentanil infusion during emergence from general anesthesia would not be inferior to high-dose remifentanil infusion alone in attenuating cough, in addition to reducing the adverse events related to high-dose remifentanil. This prospective, two parallel-group randomized, single-center noninferiority trial was aimed at comparing the efficacy of a dexmedetomidine bolus with low-dose remifentanil infusion and high-dose remifentanil infusion alone in attenuating coughing during emergence from sevoflurane-remifentanil anesthesia after thyroidectomy. The primary outcome was the severity of coughing at extubation. Secondary outcomes were the incidence of coughing during emergence from general anesthesia, which was measured three times, and recovery profiles.

\section{Materials and Methods}

\section{Patients}

This randomized controlled trial was approved by the Institutional Review Board of Gangnam Severance Hospital, Yonsei University College of Medicine, Seoul, Korea; protocol number: 3-2013-0192. This trial was registered at clinicaltrials.gov (NCT02208505); date of registration: February 2014. American Society of Anesthesiologists (ASA) class I-II adults undergoing elective thyroidectomy were enrolled in our study after providing written informed consent. Exclusion criteria included presence of an upper respiratory infection or asthma, potential problem with airway management, hepatic dysfunction, uncontrolled hypertension (systolic blood pressure $>160 \mathrm{mmHg}$ or diastolic blood pressure $>90 \mathrm{mmHg}$ ) or active coronary artery disease.

\section{Randomization}

Patients were randomly assigned to two groups in a 1:1 ratio by a computer-based randomization program (http://www.random.org/). The randomization result was kept sealed in an envelope, and only an anesthesiologist blinded to the patient assessment was allowed to open the envelope and prepare the assigned drug. Each patient received an infusion of dexmedetomidine $(0.5 \mu \mathrm{g} / \mathrm{kg})$ and low-dose remifentanil infusion at $1 \mathrm{ng} / \mathrm{mL}$ of effect-site concentration (Ce) in group DR or normal saline and high-dose remifentanil infusion at $2 \mathrm{ng} / \mathrm{mL}$ of Ce in group $\mathrm{R}$ for $10 \mathrm{~min}$ at the end of surgery.

\section{Anesthetic management}

Premedication comprised intravenous glycopyrrolate $(0.1 \mathrm{mg})$ and midazolam $(1-2 \mathrm{mg})$. Upon arrival in the operating room, standard monitors (pulse oximetry, electrocardiogram, and non-invasive blood pressure) were applied to the patients. Anesthesia was induced with propofol $(1.5 \mathrm{mg} / \mathrm{kg})$ and remifentanil $(1 \mathrm{ng} / \mathrm{mL})$ of Ce. The Ce of remifentanil using Minto's pharmacokinetic model was maintained with a commercial target-controlled infusion (TCI) system (Orchestra Base Primea; Fresenius Vial, Brezins, France). After adequate muscular relaxation with administration of intravenous rocuronium (0.6 $\mathrm{mg} / \mathrm{kg}$ ), an tracheal tube with an internal diameter of $6.5 \mathrm{~mm}$ (female) or $7.5 \mathrm{~mm}$ (male) was sited. Cuff pressure of the endotracheal tube was maintained at $20-25 \mathrm{cmH}_{2} \mathrm{O}$. The patient's lung was ventilated with a tidal volume of $8 \mathrm{~mL} / \mathrm{kg}$ of ideal body weight. Ventilation frequency was adjusted to maintain 4.6-5.3 kPa of end-tidal $\mathrm{CO}_{2}\left(\mathrm{ETCO}_{2}\right)$ partial pressure in $50 \% \mathrm{O}_{2} /$ air. During surgery, sevoflurane was adjusted to $2 \%-2.5 \%$ and remifentanil TCI was adjusted to $1.5-4.0 \mathrm{ng} / \mathrm{mL}$ to maintain heart rate and blood pressure within $20 \%$ of preoperative baseline values.

When the surgeon began placing subcutaneous sutures, inhaled sevoflurane was titrated to $1 \%$ and the Ce of remifentanil was titrated to $1 \mathrm{ng} / \mathrm{mL}$ in group DR and to $2 \mathrm{ng} / \mathrm{mL}$ in group $\mathrm{R}$ and maintained until extubation in both groups. Dexmedetomidine or normal saline was injected slowly for $10 \mathrm{~min}$ according to the group. Ketorolac $(60 \mathrm{mg})$ and ondansetron (4 mg) were administered intravenously. After completion of skin suturing, sevoflurane was turned off and 100\% oxygen flow was adjusted to 6 $\mathrm{L} / \mathrm{min}$ until the time of extubation. After confirmation of same responses visually to double-burst 
stimulation, neostigmine and glycopyrrolate were administered. Then, the $\mathrm{ETCO}_{2}$ was adjusted between 4.6-5.9 kPa with manual ventilation. The patient was stimulated gently with continuous verbal requests to open his or her eyes and light touch of the patient's shoulder at 15-s intervals. When the patient opened his or her eyes in response to stimuli and recovered full spontaneous respiration, extubation was performed. Simultaneous with extubation, remifentanil was discontinued and $100 \%$ oxygen was given via a face mask for $5 \mathrm{~min}$. All patients were transferred to the post-anesthetic care unit (PACU) after surgery.

\section{Study Endpoints and other assessments}

An anesthesiologist who did not participate in anesthesia and was blinded to the patient's treatment group assessed the severity and incidence of coughing. The severity of coughing was graded on a 4-point scale: 0 , no cough; 1 , single cough; 2 , more than one episode of unsustained cough; 3 , sustained and repetitive cough with head lift [6]. Also, severe cough was defined as cough grade 3 . Primary endpoint was the severity of coughing at the time of extubation. For the evaluation of incidence of coughing during emergence from general anesthesia as secondary outcomes, coughing was measured at three times: before extubation, at extubation, and after extubation.

Another anesthesiologist, who did not assess the coughing grade, recorded the time from discontinuation of sevoflurane to first eye opening (time to awakening) and extubation. The following parameters were recorded before induction of anesthesia, before dexmedetomidine/normal saline infusion, immediately after completion of dexmedetomidine/ normal saline infusion, and during extubation: respiratory rate, mean arterial pressure, heart rate, the Ramsay Sedation Scale. The length of a patient's stay in the PACU was recorded as were any adverse events, such as hypertension, hypotension, bradycardia ( $<60$ beats/min), oxygen desaturation $(<90 \%)$, breath-holding, laryngospasm, pain, or postoperative nausea and vomiting. Adverse events were managed according to institutional standards. Pain, postoperative nausea and vomiting, and use of analgesics and antiemetics were evaluated $24 \mathrm{~h}$ after surgery in the ward.

The quality of recovery after general anesthesia was assessed using the quality of recovery 40 item (QoR-40) questionnaire, which addresses five dimensions of recovery: physical comfort, emotional state, physical independence, psychological support, and pain. Each item was rated on a 5-point scale: none of the time, some of the time, usually, most of the time, and all of the time. The total score of the QoR-40 ranges from 40 (poor recovery) to 200 (good recovery). The QoR-40 questionnaire was administered twice, the day of surgery before the induction of general anesthesia and the day after surgery.

\section{Statistical Analysis}

Statistical analysis was performed by a medical statistician who was blinded to group allocation using SAS software 9.2 (SAS, Inc., Cary, NC, USA) and PASW statistics 23.0 Windows (SPSS, Chicago, IL, USA). The primary endpoint was the difference in cough grade at tracheal extubation. Non-inferiority design was more appropriate than equivalence design, since the clinical hypothesis was that dexmedetomidine with low-dose remifentanil could be as effective for cough suppression as high-dose remifentanil alone with lower adverse effect by opioid. Null hypothesis of the study was that dexmedetomidine with low-dose remifentanil is associated with a $<10 \%$ increase of coughing grade during extubation than high-dose remifentanil alone. The alternative hypothesis we assessed in our study for non-inferiority was that dexmedetomidine with low-dose remifentanil is associated with a $<10 \%$ increase of coughing grade during extubation than high-dose remifentanil alone. We defined our margin for non-inferiority $(10 \%)$ empirically, as we could not find any existing study that combined dexmedetomidine with low/high remifentanil to compare cough grade.

A prior study showed that the $95 \% \mathrm{CI}$ of median difference in cough grade was [0.999993, 1.999963] between two groups [7]. We assumed the non-inferiority margin to be 0.9 , and a sample size of 79 patients in each group was estimated to be required to obtain $80 \%$ power with an alpha level of 0.05 . The previous dropout rate was very low at $1 \%$ [5]. We considered the dropout rate of this study to be $8 \%$, and 85 patients per group were recruited and randomized.

All values are expressed as number of patients (percentage), mean \pm standard deviation, or median value [q1-q3 range]. The assumption of normality was checked using Shapiro-Wilk test. Discrete variables between the groups were compared using a chi-square test or Fisher's exact test. Repeated measurements were analysed using linear mixed models with a Bonferroni correction. Data were considered to be statistically significant with $p$-value less than 0.05 .

\section{Results}

Enrolled patients $(n=170)$ were randomized into the two study groups (Fig 1). In group DR, two patients did not receive the allocated intervention, 
due to a prolonged intubation time for one patient and unstable hemodynamics for the other. In group R, four patients did not receive the allocated intervention, due to prolonged intubation time for three patients and intraoperative damage to recurrent laryngeal nerve for one patient. Three patients in group DR and one patient in group $\mathrm{R}$ were excluded because of protocol violations. Four patients in each group refused to complete the QoR-40 questionnaire after surgery. They were excluded from the analysis of the quality of recovery after general anesthesia, but their characteristics and cough grade, hemodynamic stability during tracheal extubation were recorded. Demographic and surgical characteristics were similar in the two groups (Table 1).

The 95\% confidence intervals for the mean differences in cough grade at tracheal extubation were $<0.9$, which was within the margin of non-inferiority (Fig 2). The overall incidence of coughing or severe coughing (cough grade $=3$ ) was similar in the groups. In addition, the median values of cough grade during extubation were not significantly different in the two groups (Table 2).

Group $\mathrm{R}$ showed elevation of mean arterial pressure and heart rate at tracheal extubation (Fig 3), but group DR did not. During the infusion of dexmedetomidine, bradycardia ( $<60$ beats/min) was noted in 16 patients $(20 \%)$. Bradycardia resolved spontaneously after completion of the dexmedetomidine infusion, except in two patients who had hypotension (mean arterial pressure $<60 \mathrm{mmHg}$ ) with bradycardia and were treated with intravenous ephedrine (4-8 $\mathrm{mg})$.
The time to awakening and extubation were longer in group DR than in group $\mathrm{R}$ (Table 3). The trend shows better preservation of spontaneous respiration at awakening in group DR, but it didn't reach statistical significance. The length of PACU stay was not different in the two groups. Oxygen desaturation or respiratory difficulty was not observed in either group during PACU stay. Hemodynamic differences during extubation between two groups resolved spontaneously in PACU.

Table 1. Patient characteristics and intraoperative data

\begin{tabular}{lll}
\hline & Group DR $(\mathbf{n}=\mathbf{7 9})$ & Group R $(\mathbf{n}=\mathbf{8 0})$ \\
\hline Sex (M/F) & $20 / 59$ & $22 / 58$ \\
Age (years) & $43 \pm 11$ & $42 \pm 9$ \\
BMI & $24.2 \pm 3.8$ & $24.3 \pm 3.4$ \\
ASA physical status (I/II) & $62 / 17$ & $60 / 20$ \\
Smoker & $6(7 \%)$ & $5(6 \%)$ \\
Duration of anesthesia (min) & $120 \pm 36$ & $116 \pm 37$ \\
\hline
\end{tabular}

Data are presented as number of patients (\%) or mean \pm standard deviation as appropriate. NA, not applicable; BMI, body mass index; ASA, American Society of Anesthesiologists.

Table 2. Incidence and severity of coughing during emergence from anesthesia

\begin{tabular}{llll}
\hline & Group DR $(\mathbf{n}=\mathbf{7 9})$ & Group R $(\mathbf{n = 8 0})$ & $p$-value \\
\hline Incidence of: & & & \\
Any cough & $56(70 \%)$ & $65(81 \%)$ & 0.140 \\
Severe cough & $12(15 \%)$ & $14(18 \%)$ & 0.831 \\
Cough grade: & & & \\
Before extubation & $1.00 \pm 1.18$ & $0.88 \pm 1.09$ & 0.535 \\
At extubation & $0.68 \pm 0.74$ & $1.00 \pm 0.83$ & 0.012 \\
After extubation & $0.10 \pm 0.47$ & $0.23 \pm 0.69$ & 0.189
\end{tabular}

Severe cough $=$ grade 3 (sustained and repetitive coughing with head lift). Values are number (percentage) or mean \pm standard deviation.

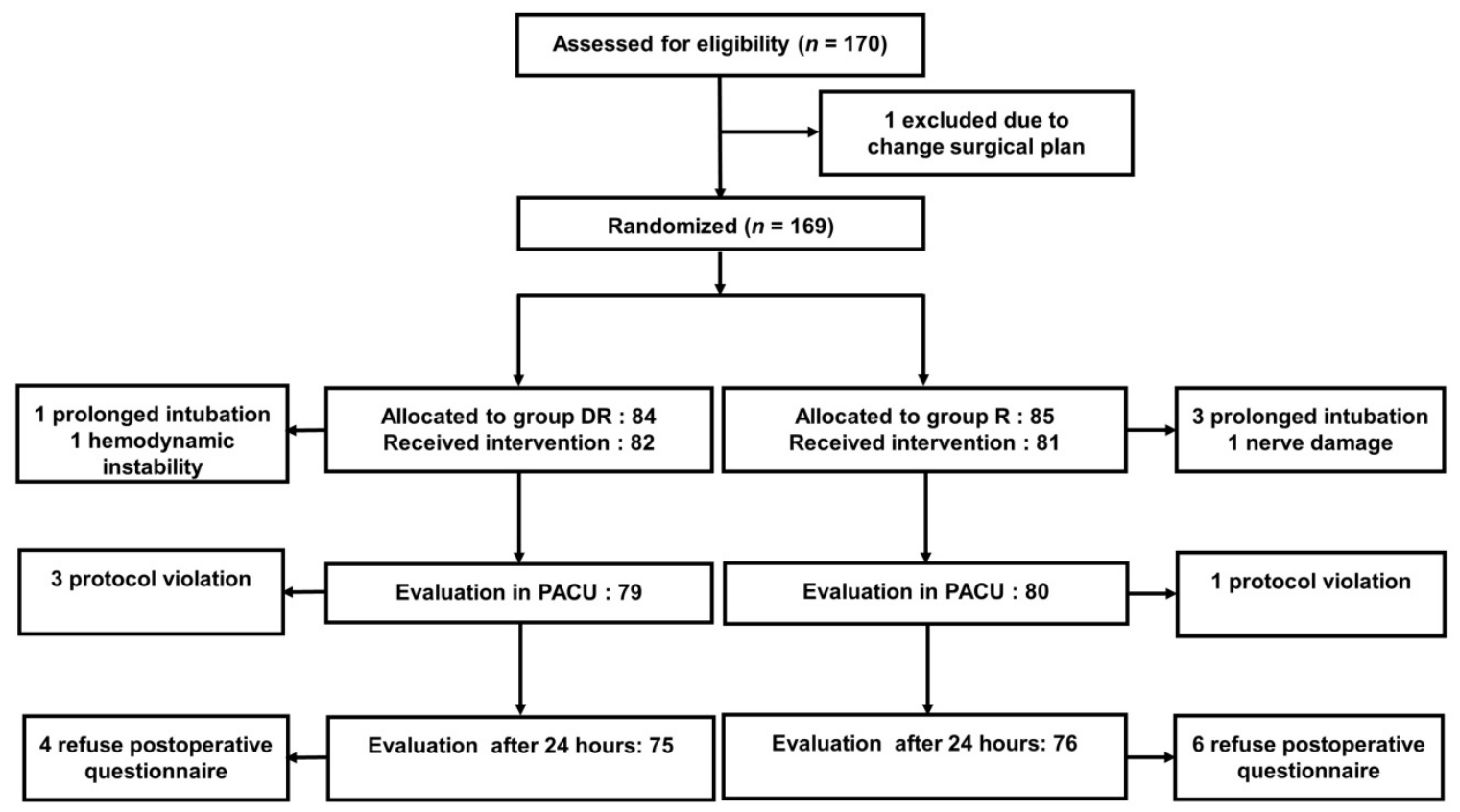

Figure 1. Consolidated Standards of Reporting Trials (CONSORT) Diagram. 


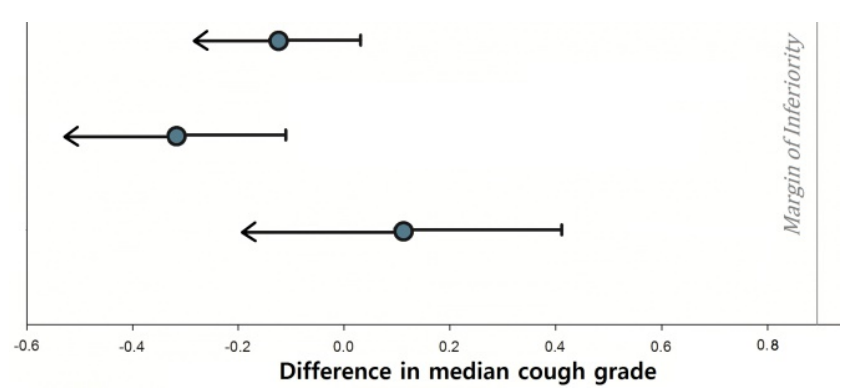

Figure 2. Differences in mean cough grade during tracheal extubation. Vertical line at 0.9 represents margin of non-inferiority for the cough grade. The horizontal bars represent one-sided $95 \%$ confidential intervals.
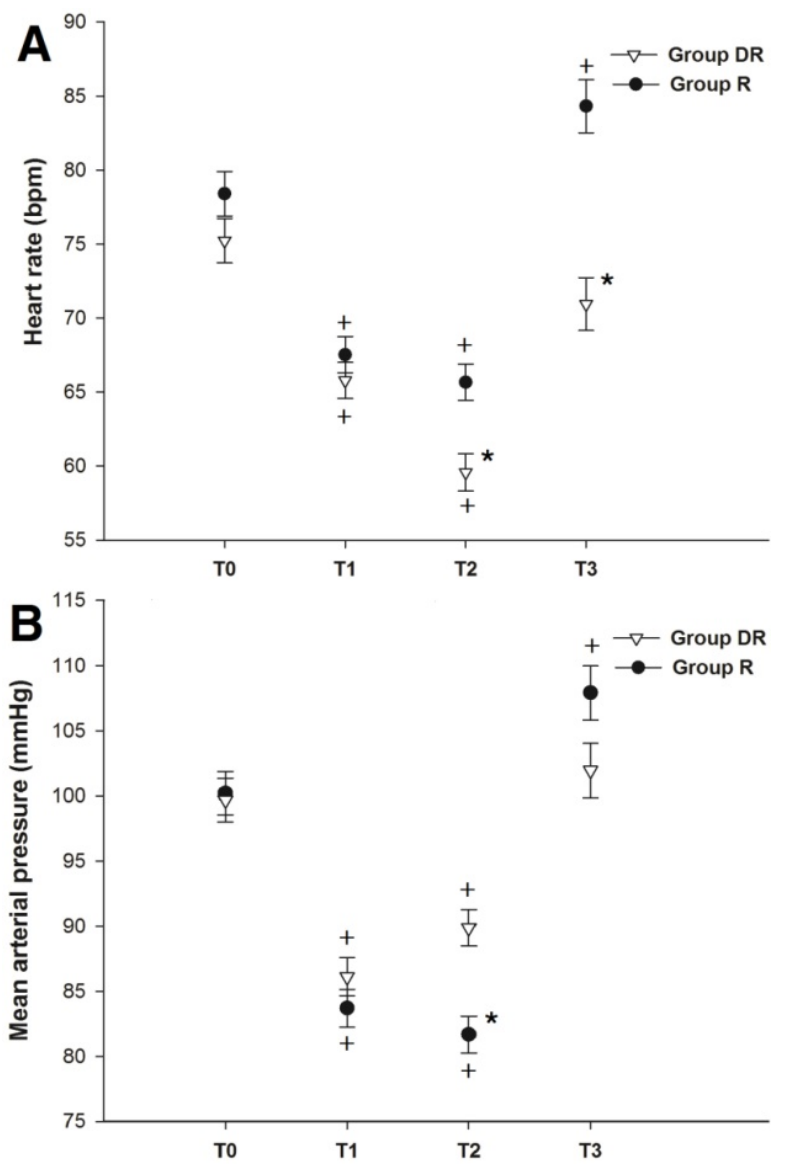

Figure 3. Hemodynamic changes during anesthesia. T0, baseline; $\mathrm{T} 1$, before infusion of dexmedetomidine or saline; T2, after infusion of dexmedetomidine or saline; T3, at extubation. $* p<0.05$ compared with placebo group (Bonferroni corrected). ${ }^{+} p<0.05$ compared with baseline in each group (Bonferroni corrected). Error bars show standard deviation.

There was no difference in the use of analgesics between two groups during the $24 \mathrm{~h}$ after surgery (Table 3). Rescue antiemetic was used more frequently in group $\mathrm{R}$ in the $24 \mathrm{~h}$ after surgery in the ward, although the difference was not significant $(p=0.086)$. However, the five patients with vomiting belonged to group $R(p=0.024)$.

The QoR-40 questionnaire was administered twice. Thus, linear mixed model was employed to examine differences in pre-/postoperative QoR-40 score between groups (Table 4). There was a significant difference between two groups in the global QoR-40 score $(\mathrm{p}=0.049)$. In each dimensional analysis, emotional state and physical independence showed difference between two groups.

\section{Discussion}

In this prospective, randomized study, we demonstrated that a single dose of dexmedetomidine $(0.5 \mu \mathrm{g} / \mathrm{kg})$ in addition to a remifentanil infusion at 1 $\mathrm{ng} / \mathrm{mL}$ of Ce during emergence from sevofluraneremifentanil anesthesia was not inferior to a remifentanil infusion alone at $2 \mathrm{ng} / \mathrm{mL}$ of Ce with regard to attenuating cough. Addition of dexmedetomidine bolus to low-dose remifentanil infusion suppressed the hemodynamic response to tracheal extubation and postoperative nausea and vomiting, although it did not improve the respiratory profile, compared to high-dose remifentanil infusion.

Table 3. Recovery profile

\begin{tabular}{|c|c|c|c|}
\hline & $\begin{array}{l}\text { Group DR } \\
(n=79)\end{array}$ & $\begin{array}{l}\text { Group R } \\
(\mathrm{n}=80)\end{array}$ & $p$-value \\
\hline Time to awakening (min) & $8 \pm 3$ & $7 \pm 2$ & $<0.001$ \\
\hline Spontaneous respiration at awakening & $34(43 \%)$ & $24(30 \%)$ & 0.101 \\
\hline Time to extubation (min) & $10 \pm 3$ & $8 \pm 2$ & 0.012 \\
\hline Ramsay score at extubation & $3[2-3]$ & $3[2-3]$ & 0.58 \\
\hline \multicolumn{4}{|l|}{ Spontaneous respiration rate $(/ \mathrm{min})$ : } \\
\hline during tracheal extubation & $13 \pm 15$ & $11 \pm 4$ & 0.315 \\
\hline 5 min after tracheal extubation & $12 \pm 4$ & $13 \pm 4$ & 0.485 \\
\hline Length of stay at PACU (min) & $50(40-60)$ & $46.5(40-60)$ & 0.868 \\
\hline Additional analgesics in PACU & $34(43 \%)$ & $45(56 \%)$ & 0.385 \\
\hline Anti-emetics in PACU & $3(4 \%)$ & $5(6 \%)$ & 0.491 \\
\hline Additional analgesics in ward & $66(84 \%)$ & $70(87 \%)$ & 0.839 \\
\hline Anti-emetics in ward & $58(73 \%)$ & $67(84 \%)$ & 0.086 \\
\hline Vomiting in ward & 0 & $5(6 \%)$ & 0.024 \\
\hline Hoarseness in ward & 0 & $4(5 \%)$ & 0.044 \\
\hline \multicolumn{4}{|c|}{$\begin{array}{l}\text { Time to awakening is the time from discontinuation of sevoflurane to spontaneous } \\
\text { eye opening or eye opening in response to light stimulation. Time to extubation is } \\
\text { the time from discontinuation of sevoflurane to extubation. PACU, post-anesthesia } \\
\text { care unit. Data are expressed as mean } \pm \text { SD, difference }(95 \% \mathrm{CI}) \text { or median [q1-q3 } \\
\text { range]. }\end{array}$} \\
\hline
\end{tabular}

Table 4. Quality of recovery questionnaire QoR-40 dimensions and global score

\begin{tabular}{llll}
\hline QoR-40 dimensions & Group DR $(\mathbf{n}=\mathbf{7 5}) *$ & Group R $(\mathbf{n}=\mathbf{7 4})$ & p-value \\
\hline Emotional state & $38.0 \pm 7.2$ & $39.5 \pm 6.3$ & 0.048 \\
Preoperative & $38.6 \pm 5.3$ & $38.4 \pm 6.3$ & \\
Postoperative & & & 0.069 \\
Physical comfort & $52.0 \pm 9.7$ & $54.1 \pm 5.6$ & \\
Preoperative & $50.8 \pm 6.0$ & $50.3 \pm 8.5$ & \\
Postoperative & & & 0.143 \\
Psychological support & $32.3 \pm 5.0$ & $33.4 \pm 2.8$ & \\
Preoperative & $32.5 \pm 3.3$ & $32.5 \pm 4.0$ & 0.038 \\
Postoperative & & & \\
Physical independence & $19.0 \pm 2.7$ & $19.5 \pm 1.3$ & 0.689 \\
Preoperative & $22.0 \pm 3.7$ & $21.1 \pm 4.0$ & \\
Postoperative & & & \\
Pain & $32.1 \pm 6.2$ & $32.1 \pm 3.4$ & 0.046 \\
Preoperative & $27.1 \pm 4.5$ & $26.6 \pm 5.6$ & \\
Postoperative & & & \\
Global QoR-40 score & $173.0 \pm 29.8$ & $178.6 \pm 16.1$ & \\
Preoperative & $171.0 \pm 19.0$ & $168.9 \pm 23.6$ & \\
Postoperative &
\end{tabular}

Values are mean $\pm \mathrm{SD}$. *Four patients in group DR and six patients in group $\mathrm{R}$ refused to complete the QoR-40 questionnaire after surgery. 
Coughing during emergence from anesthesia can result from irritant or stretch stimuli caused by the endotracheal tube [8]. Thus various methods to prevent coughing during emergence, including application of topical local anesthetics [9] and use of hypnotics [10, 11] and opioids [1, 12] to deepen anesthesia, have been tried. Further, maintenance of high-dose remifentanil during emergence was reported to be effective in reducing the incidence and severity of coughing [1]. In a previous study, additional dexmedetomidine was proven to be effective in reducing the incidence of cough after surgery [5]. Although that study demonstrated the efficacy of additional dexmedetomidine in preventing coughing, to date no study has compared the use of additional dexmedetomidine and low-dose remifentanil with high-dose remifentanil alone. Thus, the fact that we compared the two methods previously demonstrated to be effective in lowering cough strengthens our findings. Addition of dexmedetomidine to low-dose remifentanil is as effective as high-dose remifentanil in attenuating the severity and incidence of emergence cough after thyroidectomy. This protective effect of dexmedetomidine during emergence might have been due to deepening of sedation rather than a specific antitussive effect, as previously described [5, 13].

The dexmedetomidine dose was based on the previous study that concluded that addition of a single dose $(0.5 \mu \mathrm{g} / \mathrm{kg})$ of dexmedetomidine effectively attenuates coughing during emergence from sevoflurane-remifentanil anesthesia, when compared to maintenance of low-dose remifentanil infusion alone at $1 \mathrm{ng} / \mathrm{mL}$ [5]. We chose a remifentanil Ce of $2 \mathrm{ng} / \mathrm{mL}$, which is close to the $\mathrm{EC}_{95}$ of remifentanil in suppressing cough during emergence from propofol-remifentanil anesthesia [2], although Jun et al reported that remifentanil Ce of 1.5 $\mathrm{ng} / \mathrm{mL}$ reduces emergence cough from sevofluraneremifentanil anesthesia with hemodynamic stability and delayed emergence [1]. Nevertheless, the incidence of coughing in our study was slightly higher than in previous studies $[1,5,14]$, which may have resulted from the investigator's technique during tracheal extubation. Furthermore, the higher incidence may be due to the strict application of cough, which we defined as even a small head movement with contraction of the neck muscles while coughing.

Combination of dexmedetomidine and low-dose remifentanil infusion provided stable hemodynamics during emergence by attenuating cardiovascular response to tracheal extubation compared to highdose remifentanil infusion alone, although remifentanil attenuates cardiovascular change during emergence in a dose-dependent manner [1]. Unstable hemodynamics during extubation can lead to several serious clinical outcomes. Extreme high blood pressure can cause cerebral vascular events, especially in old patients, and rapid pulse rate can trigger arrhythmias. Thus, to maintain stable hemodynamics through smooth emergence is important. The results of this study can be clinically applicable in patients after head and neck major surgery, with un-ruptured cerebral aneurysm, to avoid emergence crisis - severe coughing, unstable hemodynamic changes.

During infusion of dexmedetomidine, bradycardia did occur, but blood pressure remained relatively stable, in agreement with previous studies [5, 15]. Rapid administration of dexmedetomidine can produce bradycardia or tachycardia and hypertension [3]. In this study we administered only $0.5 \mu \mathrm{g} / \mathrm{kg}$ of dexmedetomidine for $10 \mathrm{~min}$, which is half of the dose recommended by the manufacturer. Thus, hemodynamic changes during infusion of dexmedetomidine were not critical.

We expected that addition of dexmedetomidine would spare patients the adverse events of high-dose remifentanil, such as respiratory depression or postoperative nausea and vomiting, while simultaneously attenuating coughing. Dexmedetomidine in our study did not improve respiratory profiles, such as recovery of spontaneous respiration at awakening and respiration rate at extubation. Kim et al demonstrated that single dose of dexmedetomidine alone leads to better preservation of spontaneous respiration during recovery after craniotomy, compared to remifentanil infusion at $1.5 \mathrm{ng} / \mathrm{mL}$ of Ce [16]. This preserved respiration is a unique property of dexmedetomidine, in contrast to most sedatives, including opioids that depress respiration rate in a dose-dependent manner $[14,17]$. Even addition of dexmedetomidine to remifentanil does not aggravate respiratory depression induced by remifentanil [5]. So, remifentanil in this combination may play a key role in changing respiratory profiles.

Addition of dexmedetomidine suppressed postoperative nausea and vomiting in agreement with the previous studies. It remains unclear whether the antiemetic effect of dexmedetomidine might result from some property of its own or its opioid-sparing effect. The antiemetic effect of dexmedetomidine might lead to a small improvement in physical independence of QoR-40 score in the recovery profile at $24 \mathrm{~h}$ after surgery. Even, there were no significant statistical differences in the physical comfort, psychological support and pain of QoR-40 scores, the postoperative score of group DR in all categories showed smaller decrease compared with the preoperative score than group $R$. Therefore, the 
postoperative global QoR-40 score of group DR showed smaller decrease than group $R$, when compared before and after surgery. This is consistent with previous studies showing that dexmedetomidine is effective in postoperative quality of recovery in patients $[18,19]$.

Dexmedetomidine prolonged the time to awakening and extubation. This finding is consistent with the previous study that demonstrated combination of single dose of dexmedetomidine with lowdose remifentanil at $1.0 \mathrm{ng} / \mathrm{mL}$ of Ce delayed emergence compared with low-dose remifentanil alone [5]. Also, Chang et al showed that remifentanil infusion delayed emergence in a dose-dependent manner [7, 14]. In our study, dexmedetomidine combined with low-dose remifentanil at $1.0 \mathrm{ng} / \mathrm{mL}$ of Ce delayed emergence compared to high-dose remifentanil at $2.0 \mathrm{ng} / \mathrm{mL}$ of Ce. However, whether dexmedetomidine prolonged sedation during emergence remains controversial [16, 20-22]. The discrepancy among studies comes from the presence or absence of intraoperative opioids, the dose of dexmedetomidine, and patient characteristics. Therefore, clinicians should be aware that the sedative effect of dexmedetomidine might be associated with delayed awakening.

The present study has some limitations. First, the sample size was calculated for a non-inferiority trial, which generally requires a smaller sample size than a superiority trial. Thus, with a sample size 159, the present study may be underpowered to definitively assess superiority of single-dose dexmedetomidine with respect to incidence and severity of cough or secondary outcome, such as respiratory profile. Second, postoperative nausea and vomiting and pain in the ward were measured indirectly through the number of patients using analgesics or antiemetics, which can bias the postoperative patient outcome results. Third, the anesthesiologists who assessed the coughing might have been able to guess the group assignment based on the hemodynamic changes during emergence. This could potentially affect the assessment of coughing.

In conclusion, addition of a single dose of dexmedetomidine $(0.5 \mu \mathrm{g} / \mathrm{kg})$ to low-dose remifentanil infusion at $1 \mathrm{ng} / \mathrm{mL}$ of Ce during emergence from sevoflurane-remifentanil anesthesia was not inferior to a high-dose remifentanil infusion alone at $2 \mathrm{ng} / \mathrm{mL}$ of Ce for attenuating cough. Furthermore, a regimen of dexmedetomidine in addition to low-dose remifentanil maintained hemodynamic stability during emergence and reduced postoperative nausea and vomiting, compared to high-dose remifentanil alone. However, dexmedetomidine may delay emergence from general anesthesia. Therefore, addition of dexmedetomidine might be considerable alternative method for the smooth emergence from general anesthesia than the increased dose of remifentanil with attention to delayed awakening.

\section{Acknowledgements}

The authors would like to sincerely thank Hanna Yoo, PhD, and Jung Hwa Hong, MS, of Biostatistics Collaboration Lab, Yonsei University College of Medicine for their expert statistical analysis.

\section{Competing Interests}

The authors have declared that no competing interest exists.

\section{References}

1. Jun NH, Lee JW, Song JW, Koh JC, Park WS, Shim YH. Optimal effect-site concentration of remifentanil for preventing cough during emergence from sevoflurane-remifentanil anaesthesia. Anaesthesia. 2010; 65: 930-5.

2. Lee B, Lee JR, Na S. Targeting smooth emergence: the effect site concentration of remifentanil for preventing cough during emergence during propofol-remifentanil anaesthesia for thyroid surgery. British journal of anaesthesia. 2009; 102: 775-8.

3. Bhana N, Goa KL, McClellan KJ. Dexmedetomidine. Drugs. 2000; 59: 263-8; discussion 9-70.

4. Gerlach AT, Dasta JF. Dexmedetomidine: an updated review. The Annals of pharmacotherapy. 2007; 41: 245-52.

5. Lee JS, Choi SH, Kang YR, Kim Y, Shim YH. Efficacy of a single dose of dexmedetomidine for cough suppression during anesthetic emergence: a randomized controlled trial. Canadian journal of anaesthesia = Journal canadien d'anesthesie. 2015; 62: 392-8.

6. Minogue SC, Ralph J, Lampa MJ. Laryngotracheal topicalization with lidocaine before intubation decreases the incidence of coughing on emergence from general anesthesia. Anesthesia and analgesia. 2004; 99: 1253-7, table of contents.

7. Lee JH, Koo BN, Jeong JJ, Kim HS, Lee JR. Differential effects of lidocaine and remifentanil on response to the tracheal tube during emergence from general anaesthesia. British journal of anaesthesia. 2011; 106: 410-5.

8. Fagan C, Frizelle HP, Laffey J, Hannon V, Carey M. The effects of intracuff lidocaine on endotracheal-tube-induced emergence phenomena after general anesthesia. Anesthesia and analgesia. 2000; 91: 201-5.

9. Shroff PP, Patil V. Efficacy of cuff inflation media to prevent postintubation-related emergence phenomenon: air, saline and alkalinized lignocaine. European journal of anaesthesiology. 2009; 26: 458-62.

10. Jung SY, Park HB, Kim JD. The effect of a subhypnotic dose of propofol for the prevention of coughing in adults during emergence from anesthesia with sevoflurane and remifentanil. Korean journal of anesthesiology. 2014; 66: 120-6.

11. Pak HJ, Lee WH, Ji SM, Choi YH. Effect of a small dose of propofol or ketamine to prevent coughing and laryngospasm in children awakening from general anesthesia. Korean journal of anesthesiology. 2011; 60: 25-9.

12. Kim H, Choi SH, Choi YS, Lee JH, Kim NO, Lee JR. Comparison of the antitussive effect of remifentanil during recovery from propofol and sevoflurane anaesthesia. Anaesthesia. 2012; 67: 765-70.

13. Ryu JH, Lee SW, Lee JH, Lee EH, Do SH, Kim CS. Randomized double-blind study of remifentanil and dexmedetomidine for flexible bronchoscopy. British journal of anaesthesia. 2012; 108: 503-11.

14. Chang CH, Lee JW, Choi JR, Shim YH. Effect-site concentration of remifentanil to prevent cough after laryngomicrosurgery. The Laryngoscope. 2013; 123: 3105-9.

15. Wang T, Ge S, Xiong W, Zhou P, Cang J, Xue Z. Effects of different loading doses of dexmedetomidine on bispectral index under stepwise propofol target-controlled infusion. Pharmacology. 2013; 91: 1-6.

16. Kim H, Min KT, Lee JR, Ha SH, Lee WK, Seo JH, et al. Comparison of Dexmedetomidine and Remifentanil on Airway Reflex and Hemodynamic Changes during Recovery after Craniotomy. Yonsei Med J. 2016; 57: 980-6.

17. Hsu YW, Cortinez LI, Robertson KM, Keifer JC, Sum-Ping ST, Moretti EW, et al. Dexmedetomidine pharmacodynamics: part I: crossover comparison of the respiratory effects of dexmedetomidine and remifentanil in healthy volunteers. Anesthesiology. 2004; 101: 1066-76.

18. Bekker A, Haile M, Kline R, Didehvar S, Babu R, Martiniuk F, et al. The effect of intraoperative infusion of dexmedetomidine on the quality of recovery after major spinal surgery. Journal of neurosurgical anesthesiology. 2013; 25: 16-24.

19. Kim SH, Oh YJ, Park BW, Sim J, Choi YS. Effects of single-dose dexmedetomidine on the quality of recovery after modified radical 
mastectomy: a randomised controlled trial. Minerva anestesiologica. 2013; 79: 1248-58

20. Guler G, Akin A, Tosun Z, Eskitascoglu E, Mizrak A, Boyaci A. Single-dose dexmedetomidine attenuates airway and circulatory reflexes during extubation. Acta anaesthesiologica Scandinavica. 2005; 49: 1088-91.

21. Guler G, Akin A, Tosun Z, Ors S, Esmaoglu A, Boyaci A. Single-dose dexmedetomidine reduces agitation and provides smooth extubation after pediatric adenotonsillectomy. Paediatric anaesthesia. 2005; 15: 762-6.

22. Kim SY, Kim JM, Lee JH, Song BM, Koo BN. Efficacy of intraoperative dexmedetomidine infusion on emergence agitation and quality of recovery after nasal surgery. British journal of anaesthesia. 2013; 111: 222-8. 